\title{
A Variable Speed Control of Permanent Magnet Synchronous Motor Without Current Sensors
}

\author{
Younes Azzoug ${ }^{1,2}$, Mohamed Sahraoui ${ }^{1,3}$, Remus Pusca ${ }^{2}$, Tarek Ameid ${ }^{2}$, Raphaël Romary ${ }^{2}$, Antonio J. Marques \\ Cardoso ${ }^{3}$ \\ ${ }^{1}$ Department of Electrical Engineering of the University of Biskra, Laboratory of Electrical Engineering of Biskra (LGEB), \\ Biskra, Algeria \\ ${ }^{2}$ Faculty of Applied Science, Univ. Artois, UR 4025 LSEE F-62400, Bethune, France \\ ${ }^{3}$ CISE - Electromechatronic Systems Research Centre, University of Beira Interior, Covilhã, Portugal \\ younes.azzoug@univ-biskra.dz, m.sahraoui@univ-biskra.dz,remus.pusca@univ-artois.fr, tarek.ameid@ieee.org, raphael.romary@univ- \\ artois.fr, ajmcardoso@ieee.org
}

\begin{abstract}
This paper introduces a simple and low-cost direct vector control method without current sensors for Permanent Magnet Synchronous Motor (PMSM) drives, using only a single estimator and the measured dc-link voltage, as well as the measured rotor speed for currents reconstruction. The proposed method is based on a new modification of the adaptive state observer to estimate the line currents. A theoretical concept is developed, the modified adaptive state observer is presented. Simulations tests are performed to prove the ability of the proposed scheme to reconstruct stator currents and reproduce the performances of a basic and traditional vector control PMSM drive.
\end{abstract}

Keywords- Permanent magnet synchronous motor; current sensorless; adaptive state observer; vector control;

\begin{tabular}{|c|c|}
\hline \multicolumn{2}{|c|}{ NOMENCLATURE } \\
\hline$V_{s d}, V_{s q}$ & $d-q$ axes stator voltages \\
\hline$I_{s d}, I_{s q}$ & $d$-q axes stator currents \\
\hline$\hat{I}_{s d}, \hat{I}_{s q}$ & $\begin{array}{l}d \text {-q axes estimated stator } \\
\text { currents }\end{array}$ \\
\hline$L_{d}, L_{q}$ & $\begin{array}{l}\text { Direct and quadrature } \\
\text { inductances }\end{array}$ \\
\hline$T_{e m}, T_{l}$ & $\begin{array}{l}\text { Electromagnetic and load } \\
\text { torques }\end{array}$ \\
\hline$\Omega_{r}^{*}, \Omega_{r-m e s}$ & $\begin{array}{l}\text { Reference and measured } \\
\text { mechanical speeds }\end{array}$ \\
\hline$I_{s a-m e s}, I_{s b-m e s}, I_{s c-m e s}$ & $\begin{array}{l}(a, b, c) \text { axes measured stator } \\
\text { currents }\end{array}$ \\
\hline$I_{s a-e s t}, I_{s b-e s t}, I_{s c-e s t}$ & $\begin{array}{l}(a, b, c) \text { axes estimated stator } \\
\text { currents }\end{array}$ \\
\hline
\end{tabular}

\section{INTRODUCTION}

The development in a selected number of fields such as spacecraft, aircraft, railway and electrical vehicles focuses on Permanent Magnet Synchronous Motors (PMSMs) due to their high torque density, efficiency, simple structure and high-speed operation range [1]. Different methods are proposed for PMSM variable speed drive, which generally needs feedback information from a position encoder, two current sensors and dc-link voltage sensor at least [2], [3]. Unfortunately, sensors are very prone to failures and in most cases, they increase the cost of the system as well as, they are not easy to implement in applications that do not provide access to enough space. So, the best way to act is to reduce the number of sensors as much as possible, provided that the system performances are maintained.

In the literature, several methods have been developed for PWM inverters and AC electrical motor variable speed drives in order to reduce the number of current sensors [4]-[25]. The aim of minimizing the number of sensors in the control loops due to of many reasons, such as, reducing the costs and system volume, avoiding problems of inaccurate acquisition due to sever and noisy environments, as well as, protect the control system from any damage caused by sensor failures. In the references [4]-[15], [17]-[19], [22] and [23], the general proposed methods of the authors to minimize current sensors is the idea that relies on measuring dc-bus current to reconstruct the three phase currents using the switching control signals generated by the Voltage Source Inverter Power Width Modulation (VSI-PWM). As summarized in [1], [8], [9], [22] and [23], the methods based on the conventional PWM switching control signals and dc-bus current present some limits because of the dead zones, in consequence, the acquisition of the dc-link current will not be available since the lifetime of the active voltage vector is lower compared to the minimum time needed for current measurement. On the whole, those papers suggest powerful solutions to overcome this problem modifying the switching control signals, but to sum up, they still use a current sensor in the dc-link VSI which is not enough to achieve a good performance in variable speed drive. However, other research has succeeded in the current sensorless control. The authors in [16] propose a direct torque control algorithm for induction motor without AC phase current sensors, this method does not require additional computation burden or other motor parameter knowledge, but, a voltage divider and shunt resistor were added in the dc-link of the VSI to estimate the stator currents using the switching lookup table signals. In [20], [21], the authors propose a direct predictive control without current sensors for the induction motor and permanent magnet synchronous motor, where the future values of the stator currents are estimated by a prediction-correction algorithm. The results obtained in those papers suggest that at rated load condition, the performance is worse than that under a no-load condition. In [24], an estimator 
for the line currents is proposed, based on flux and torque equations. This idea is suggested for current sensors faulttolerant control. Although the drive runs with a dc-link voltage sensor and a speed sensor, however, this is not a permanent solution as the drive becomes highly sensitive to the machine parameters.

This paper presents a PMSM direct vector control without AC current sensors feedback. This method uses an approach that relies on a new modification of the adaptive state observer, based on the motor model to reconstruct the stator currents. The drive runs only with a single voltage sensor in the VSI dclink and a speed/position sensor, in other word, without any current sensor. The proposed method had achieved promising results on induction motor speed control [25]. In this respect, the method is adopted for the PMSM variable speed drive, where a simulation tests are performed to evaluate the currents estimator in PMSM control system.

The remainder of the paper is organized into VI sections, where the mathematical model of PMSM is described in section II. Section III analyses the direct vector control of PMSM and the proposed method for currents reconstruction is introduced in section IV. Afterward, the simulation tests are presented in section $\mathrm{V}$ and discussed. At the end, section VI concludes the paper.

\section{MODEL OF THE PMSM}

The model of the PMSM can be represented mathematically by two differential equations of the stator currents in the synchronous reference frame $(d, q)$, described by the following expressions:

$$
\left\{\begin{array}{l}
\frac{d I_{s d}}{d t}=\frac{1}{L_{d}}\left(-R_{s} I_{s d}+\omega_{r e} L_{q} I_{s q}+V_{s d}\right) \\
\frac{d I_{s q}}{d t}=\frac{1}{L_{q}}\left[-R_{s} I_{s q}-\omega_{r e}\left(L_{q} I_{s d}+\varphi_{r}\right)+V_{s q}\right]
\end{array}\right.
$$

The PMSM model presented in (1) can be written in the following state equation:

$$
\dot{x}=H x+D u
$$

where:

$$
\begin{gathered}
H=\left[\begin{array}{cc}
-\frac{R_{s}}{L_{d}} & \frac{L_{q}}{L_{d}} \omega_{r e} \\
-\frac{L_{q}}{L_{d}} \omega_{r e} & -\frac{R_{s}}{L_{q}}
\end{array}\right] ; x=\left[\begin{array}{c}
I_{s d} \\
I_{s q}
\end{array}\right] ; \\
D=\left[\begin{array}{ccc}
\frac{1}{L_{d}} & 0 & 0 \\
0 & \frac{1}{L_{q}} & -\frac{1}{L_{q}} \omega_{r e}
\end{array}\right] ; u=\left[\begin{array}{c}
V_{s d} \\
V_{s q} \\
\phi_{r}
\end{array}\right]
\end{gathered}
$$

Whereas, the electromagnetic torque can be computed by the following equation:

$$
T_{e m}=p\left[\left(L_{d}-L_{q}\right) I_{s d} I_{s q}+\varphi_{r} I_{s q}\right]
$$

The conversion of electrical energy into mechanical energy in rotating machines is determined by the following relation:

$$
J \frac{d \Omega_{r}}{d t}=T_{e m}-T_{l}-F \Omega_{r}
$$

\section{DIRECT VECTOR CONTROL OF PMSM}

In high-power machines, the current regulation is required similarly like the torque should be controlled with accuracy, in order to avoid saturation due to high currents passing through the stator magnetic circuit. So, the direct vector control of the PMSMs consists in regulating the direct and quadratic currents as well as the speed, this control strategy is adopted in this paper.

The basic scheme of PMSM direct vector control is presented in Fig. 1.

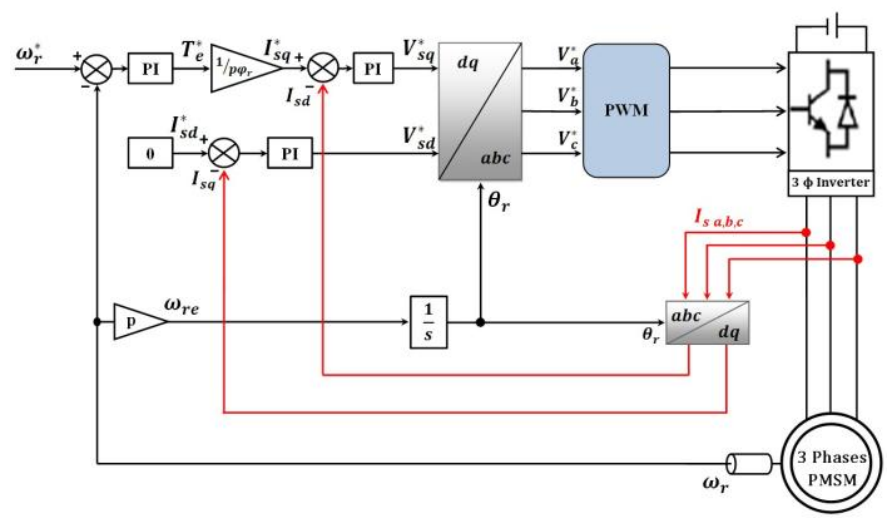

Figure 1. Basic scheme of PMSM's direct vector control.

\section{PRINCIPALE OF VARIABLE SPEED DRIVE WITHOUT CURRENT SENSORS}

In order to estimate the three-phase currents, an adaptive state observer is used, based on the PMSM model described in (2).

The idea of the proposed stator currents estimator is based on the general theory of an adaptive state observer [26], which allows the estimation of variable or unknown parameters of a non-linear system. The equation of the adaptive state observer is expressed in (5), where the symbol " $\wedge$ " denotes the estimated values.

$$
\dot{\hat{x}}=H \hat{x}+D u+G \lambda
$$

where:

$$
\hat{x}=\left[\begin{array}{c}
\hat{I}_{s d} \\
\hat{I}_{s q}
\end{array}\right] ; \lambda=\left[\begin{array}{c}
I_{s d}-\hat{I}_{s d} \\
I_{s q}-\hat{I}_{s q}
\end{array}\right]
$$

Since there is no information about the measured currents, the vector $\lambda$ becomes: 


$$
\lambda=\left[\begin{array}{l}
-\hat{I}_{s d} \\
-\hat{I}_{s q}
\end{array}\right]
$$

The gain matrix $G$ is defined as described in [27] using pole placement method:

$$
G=\left[\begin{array}{cc}
g_{1} & 0 \\
0 & g_{2}
\end{array}\right]
$$

where:

$$
\left\{\begin{array}{l}
g_{1}=k \frac{R_{s}}{L_{d}} \\
g_{2}=k p \omega_{r e}
\end{array}\right.
$$

and $k$ is a positive constant.

The estimation is performed throw the conservation of the state model (2) of the PMSM with the gain matrix $G$ to ensure the convergence of the estimator. Then, replacing the adaptive mechanism loop by the measured rotational speed, as well as, feeding the observer with the stator voltages provided by the voltage synthesizer. This gives the stator currents estimation, as illustrated in Fig. 2.

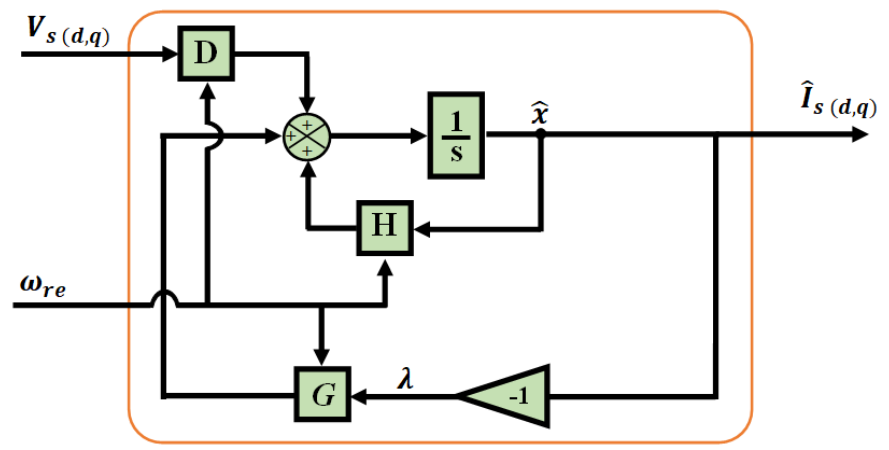

Figure 2. Scheme of the proposed stator currents estimator of the PMSM.

The overall scheme of the proposed current sensorless direct vector control of the PMSM is presented in Fig. 3.

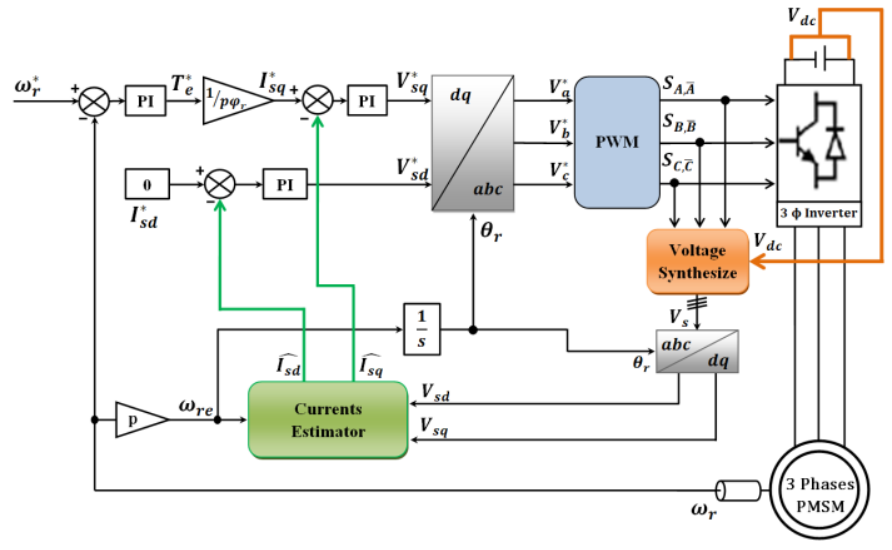

Figure 3. Scheme of the PMSM direct vector control without using current sensors.

\section{Simulation Results AND Discussion}

To verify the workability of the proposed current sensorless method, simulation tests have been performed in Matlab/Simulink under different conditions such as low-speed test, variable speed and variable load application. The obtained results applying the current sensorless direct vector control on PMSM are presented and discussed in the following subsections.

In order to achieve the simulation tests, parameters of an existing PMSM in our laboratory are used, which are reported in the Appendix.

\section{A. Variable Speed and Variable Load Application test}

In this test, a variable speed profile has been used as the reference speed, starting from $0 \mathrm{rpm}$ to $1500 \mathrm{rpm}$ and growing up until $3000 \mathrm{rpm}$ the nominal speed of PMSM, after that, the reference speed decreases until $0 \mathrm{rpm}$, then increases to 900 rpm.

Reference and measured rotor speeds are plotted in Fig. 4(a), where we can see a good fulfillment of the rotor speed to the reference one. Also, during this test at variable speed, different load levels have been applied. As can be seen in Fig. 4(b), a load step of $7 N$ was imposed at $t=1 \mathrm{~s}$ with a speed of $1500 \mathrm{rpm}$. Afterwards and when the PMSM rotor speed was $3000 \mathrm{rpm}$, the load was increased to $15 \mathrm{~N}$ at $t=1.8 \mathrm{~s}$.

The results shows uninterrupted fulfillment of load torque requirement under these conditions.

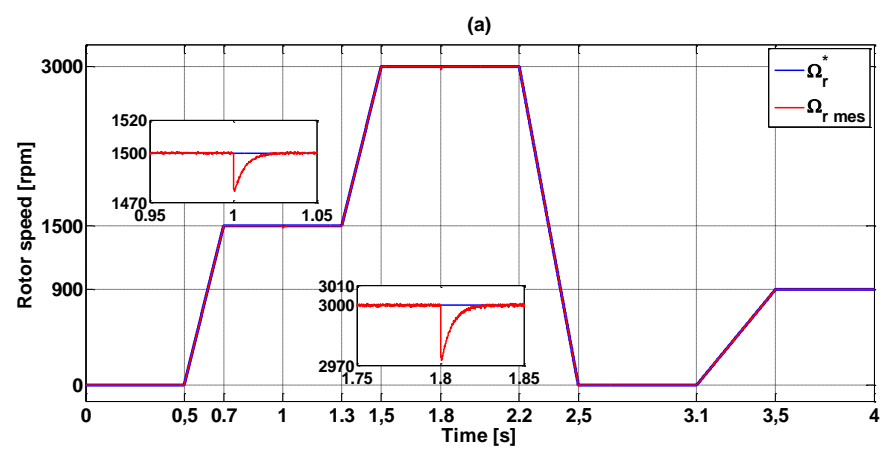

(b)

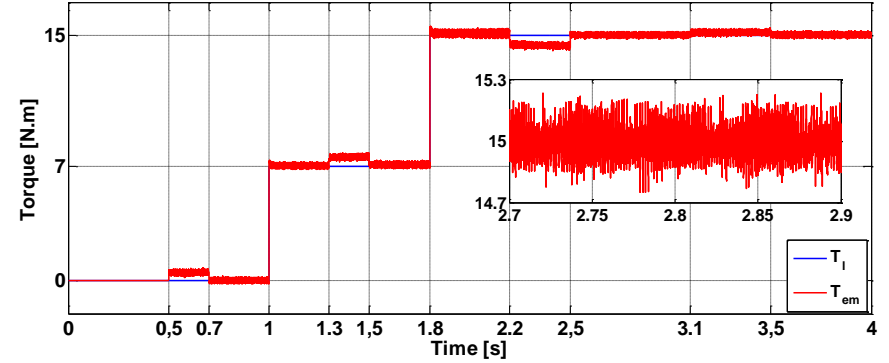

Figure 4. Rotor speed and torque in variable speed and varable load test: (a) reference and measured rotor speeds, (b) load and electromagnetic torques.

Consider Fig. 5 which presents estimated (reconstructed) and real currents throughout speed and load variation test. When we focus on the zoom of each subfigure, we can see a proper reconstruction of the $\mathrm{AC}$ phase currents at each stage of the test. 
Given that the considered system is a non-linear one, the Benchmark test for dynamic systems was applied to confirm that the current estimator presented in this paper is operational at all points of the operating system. In this test disturbances such as speed and load variation are considered, which shows that the proposed method without current sensors achieves the same performances as with current sensors.

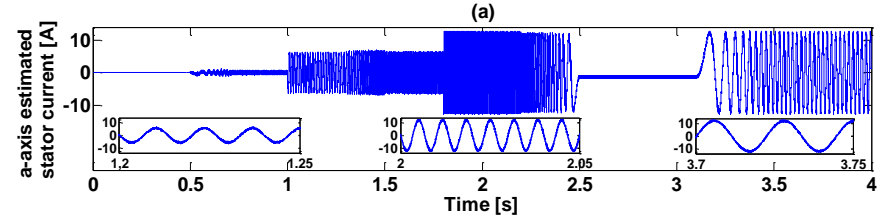

(b)

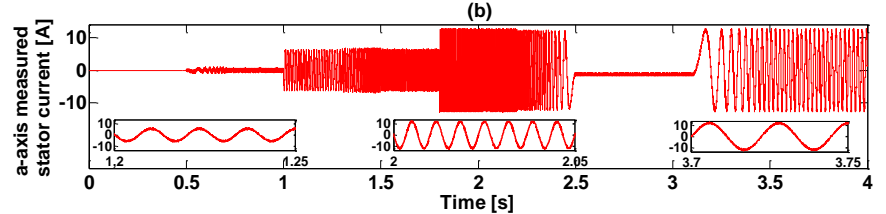

(c)

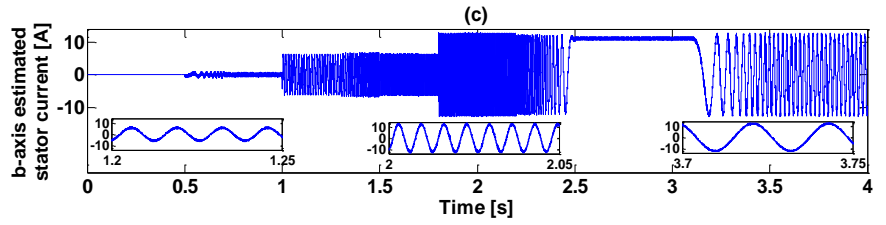

(d)

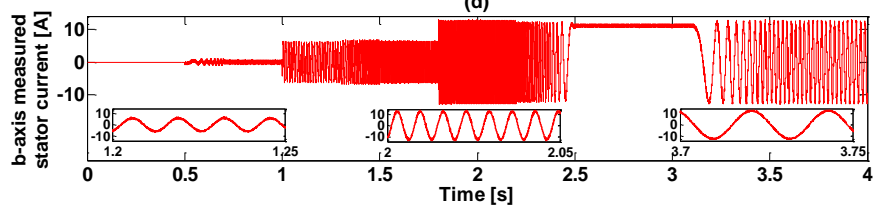

(e)

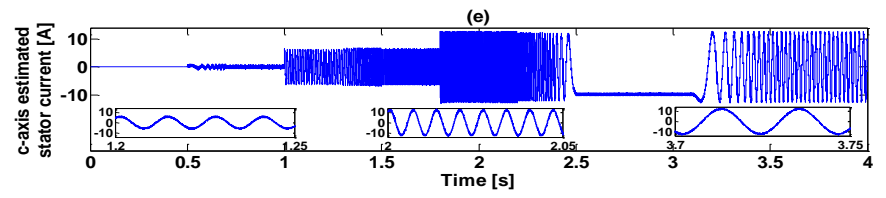

(f)

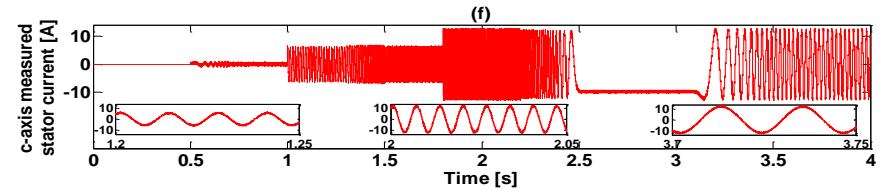

Figure 5. Estimated and actual stator currents in variable speed and load test: (a) a-axis estimate stator current, (b) a-axis actual stator current, (c) b-axis estimated stator current, (d) b-axis actual stator current, (e) c-axis estiamted stator current and (f) c-axis actual stator current.

In order to illustrate the accuracy and the performance of the proposed currents estimator, the estimation errors in phasea, phase-b and phase-c are given in Figs. 6(a), 6(b) and 6(c) in succession knowing that the plotted errors below are calculated during variable speed and load test (Benchmark test). As can be seen from these figures, the maximum error in the steady-state is approximately $0.5 \mathrm{~A}(3.84 \%$ of the magnitude of the machine rated current) and $1.19 \mathrm{~A}(9.15 \%$ of the magnitude of the machine rated current) in the transient state, which can qualify the high accuracy estimation.
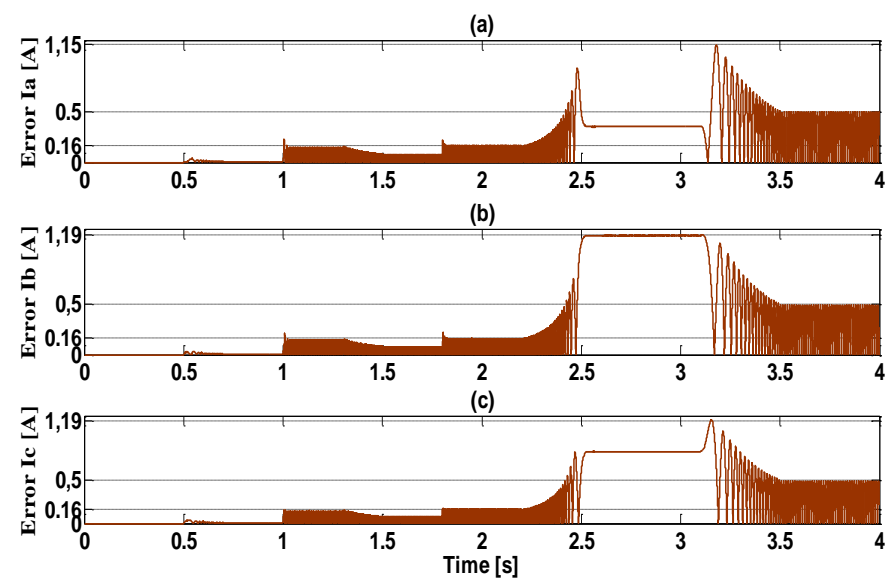

Figure 6. Estimation errors at variable speed and load test: (a) a-axis currents estimation error, (b) b-axis currents estimation error and (c) c-axis currents estimation error.

\section{B. Low-Speed Test}

In AC electrical variable speed drives, a low-speed test is very important to be performed. This allows highlighting the high-quality of the control system performance or their improvements. In this regard, the proposed current sensorless method is tested at low-speed (70 rpm $2.33 \%$ nominal speed) with rotation direction reverse and rated load (15 N). In Figs. 7 (a) and 7(b), the reference speed, the measured rotor speed and the electromagnetic torque are presented consecutively.

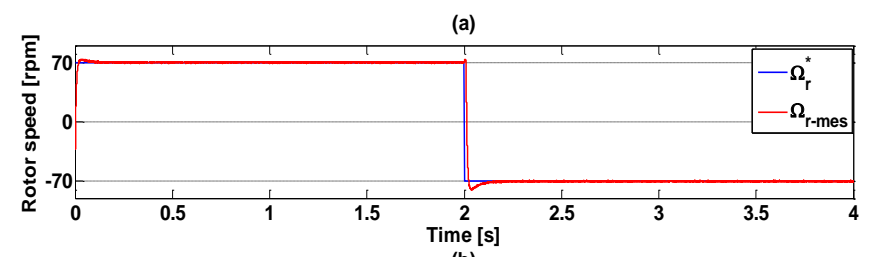

(b)

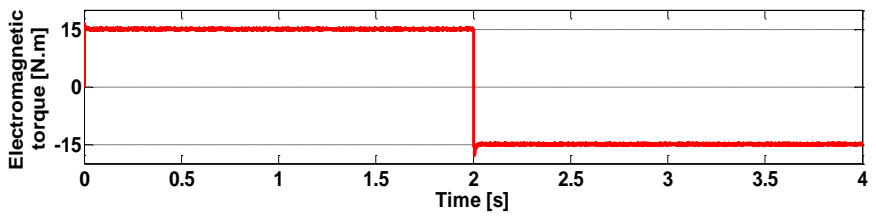

Figure 7. Rotor speed and torque in low-speed test: (a) reference and measured rotor speeds, (b) electromagnetic torque.
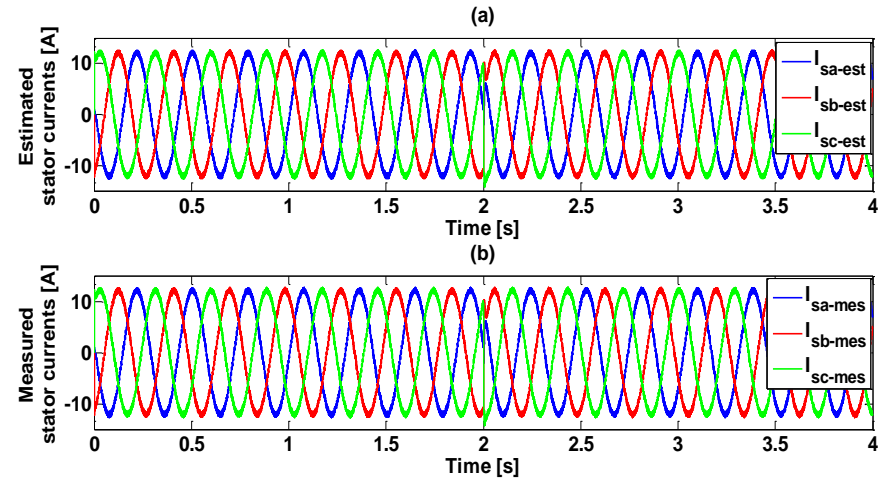

Figure 8. Estimated and actual stator currents in low-speed test: (a) three phase estimated stator currents, (b) three phase actual stator currents. 
A high-performance estimation of the three-phase stator currents was carried out by the proposed technique under lowspeed test which is proved by the good match between the estimated currents plotted in Fig. 8(a) and actual currents plotted in Fig. 8(b).

\section{Test of Robustness versus Parameter Variation}

Robustness versus parameter variation is an important test to perform. Fig. 9 presents mechanical (speed and electromagnetic torque) and electrical (direct and quadrature stator currents) measurements during the parameter variation test. The considered parameters for variation are stator resistance $\left(R_{s}\right)$, direct and quadrature inductances $\left(L_{d}\right.$ and $L_{q}$ which are equal) (see the appendix).
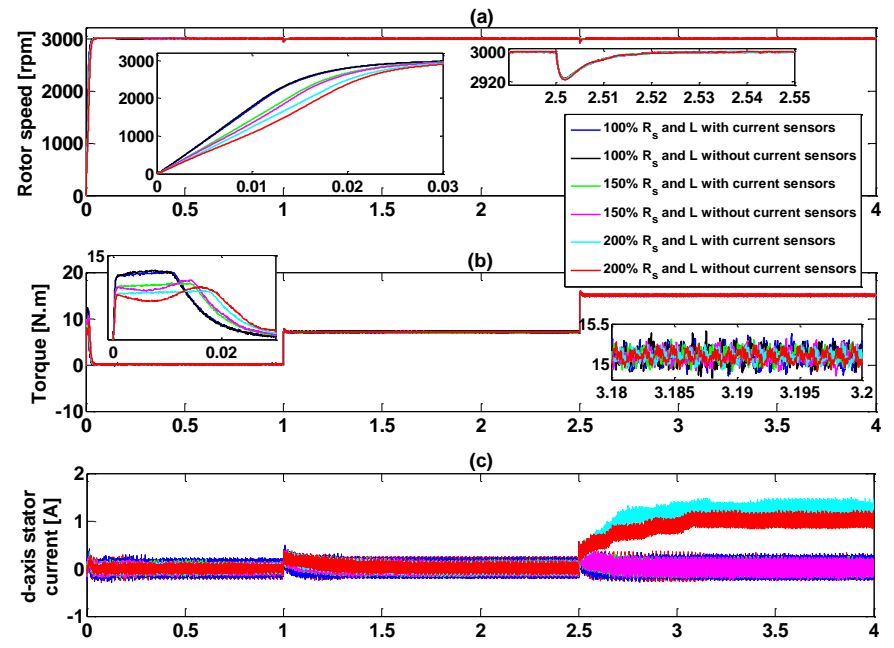

(d)

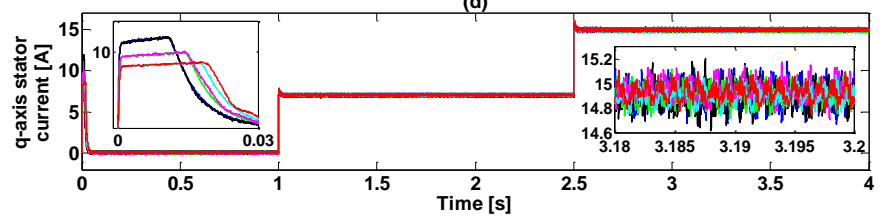

Figure 9. Parameters variation test: (a) rotor speed, (b) electromagnetic torque, (c) direct stator current and (d) quadrature stator current.

Such cases are depicted in Fig. 9, where, the parameter variation is about $150 \%$ and $200 \%$ of the actual values, with and without current sensors. So, it is possible to compare the performances and the robustness of the proposed sensorless method with those of with current sensors. The test is performed at rated speed $(3000 \mathrm{rpm})$ and three stages of load application; the first one is from 0 to $1 \mathrm{~s}$ with no load, the second one from 1 to $2.5 \mathrm{~s}$ with $50 \%$ of rated load and the last one is from 2.5 to $4 \mathrm{~s}$ with rated load $(15$ N.m). We can see that the parameter variation doesn't affect the robustness of the system significantly. The consequence of this variation is that the response time is increased by a few ms as shown in Figs. 9(a), 9(b) and 9(d) where rotor speed, electromagnetic torque and quadrature current are plotted in succession. Also, the direct current is increased from 0 to $1 \mathrm{~A}$ at rated load as can be seen in Figs. 9(c), this increase will cause a slight increase in the amplitude of the stator currents.

Furthermore, the results show that the proposed current sensorless method has the same robustness as with current sensors.

\section{CONCLUSION}

This paper proposes a PMSM direct vector control without current sensors. The proposed method for currents estimation is simple and effective to use. In this paper a particular attention is paid to reduce the number of sensors in the control system as much as possible providing that the system performance are maintained, not only in order to minimize the costs of the system but also to avoid problems of inaccurate acquisition due to sever and noisy environments, as well as, to protect the control system from consequences of current sensors failure. Comparing to the works already published, the suggested method for currents estimation does not use any additional sensors, which qualifies the originality of this research. This method is based on currents estimator and existing sensors in the system namely VSI dc-link sensor and speed/position sensor. The effectiveness of the proposed current sensorless control algorithm was verified by simulation in Matlab/Simulink. Based on the obtained results, it can be concluded that the findings are very promising, where we can see that the reconstructed currents are similar to the measured ones. On the basis of the promising simulation results presented in this paper, work on the remaining issue is continuing and aims to an experimental implementation on the laboratory test bench, in addition to an experimental limitation study on the regards of the real parametric variation.

Finally, the suggested sensorless method can be a solution for current sensors fault tolerant control PMSM drives.

\begin{tabular}{|c|c|c|c|}
\hline \multicolumn{4}{|c|}{ APPENDIX } \\
\hline \multicolumn{2}{|l|}{ Specifications } & \multicolumn{2}{|c|}{ Parameters } \\
\hline Nominal power $[\mathrm{kW}]$ & 4.8 & $\mathrm{R}_{\mathrm{s}}[\Omega]$ & 0.9 \\
\hline Nominal voltage [V] & 400 & $\mathrm{~L}_{\mathrm{d}}[\mathrm{H}]$ & 0.009 \\
\hline Nominal current $[\mathrm{A}]$ & 9.6 & $\mathrm{~L}_{\mathrm{q}}[\mathrm{H}]$ & 0.009 \\
\hline Frequency [Hz] & 150 & $\varphi_{\mathrm{r}}[\mathrm{Wb}]$ & 0.225 \\
\hline Number of pole pairs & 3 & $\mathrm{~J}\left[\mathrm{Kg} \cdot \mathrm{m}^{2}\right]$ & 0.000629 \\
\hline Nominal speed [rpm] & 3000 & $\mathrm{f}\left[\mathrm{Nm} \cdot \mathrm{s} \cdot \mathrm{rad}^{-1}\right]$ & 0.0003025 \\
\hline Nominal torque [N.m] & 15.3 & & \\
\hline \multicolumn{4}{|c|}{ Simulation settings } \\
\hline Sampling time $[\mathrm{s}]$ & 0.00001 & $\mathrm{Kp}\left(\mathrm{I}_{\mathrm{sd}}\right.$ regulator $)$ & 5.4 \\
\hline Switching frequency $[\mathrm{Hz}]$ & 5000 & $\mathrm{Ki}\left(\mathrm{I}_{\mathrm{sd}}\right.$ regulator $)$ & 100 \\
\hline Kp (speed regulator) & 0.5848 & $\mathrm{Kp}\left(\mathrm{I}_{\mathrm{sq}}\right.$ regulator $)$ & 5.4 \\
\hline Ki (speed regulator) & 91.87 & $\mathrm{Ki}\left(\mathrm{I}_{\mathrm{sq}}\right.$ regulator $)$ & 100 \\
\hline
\end{tabular}

\section{ACKNOWLEDGMENT}

This work has been achieved within the framework of CE2I project (Convertisseur d'Energie Intégré Intelligent). CE2I is co-financed by European Union with the financial support of the European Regional Development Fund (ERDF), French State and the French Region of Hauts-de-France.

As well, this work was supported by the European Regional Development Fund (ERDF) through the Operational Program for Competitiveness and Internationalization - COMPETE 2020, and also by National Funds through the Portuguese Foundation for Science and Technology (FST), under Project POCI-01-0145-FEDER-029494 and Project UID/EEA/04131/2013. 


\section{REFERENCES}

[1] A. Loganayaki and R. B. Kumar, "Permanent Magnet Synchronous Motor for Electric Vehicle Applications," in 2019 5th International Conference on Advanced Computing \& Communication Systems (ICACCS), 2019, pp. 1064-1069.

[2] M. H. Vafaie, B. Mirzaeian Dehkordi, P. Moallem, and A. Kiyoumarsi, "A New Predictive Direct Torque Control Method for Improving Both Steady-State and Transient-State Operations of the PMSM," IEEE Trans. Power Electron., vol. 31, no. 5, pp. 3738-3753, May 2016.

[3] Y. Inoue, S. Morimoto, and M. Sanada, "Comparative Study of PMSM Drive Systems Based on Current Control and Direct Torque Control in Flux-Weakening Control Region," IEEE Trans. Ind. Appl., vol. 48, no. 6, pp. 2382-2389, Nov. 2012.

[4] F. Blaabjerg, "An ideal PWM-VSI inverter using only one current sensor in the DC-link," in Proceedings of 5th International Conference on Power Electronics and Variable-Speed Drives, 1994, vol. 1994, no. 399, pp. $458-464$.

[5] Woo-Cheol Lee, Taeck-Kie Lee, and Dong-Seok Hyun, "Comparison of single-sensor current control in the DC link for three-phase voltagesource PWM converters," IEEE Trans. Ind. Electron., vol. 48, no. 3, pp. 491-505, Jun. 2001.

[6] Dong-Choon Lee and Dae-Sik Lim, "AC voltage and current sensorless control of three-phase PWM rectifiers," IEEE Trans. Power Electron., vol. 17, no. 6, pp. 883-890, Nov. 2002.

[7] T. M. Wolbank and P. E. Macheiner, "Current-Controller With Single DC Link Current Measurement for Inverter-Fed AC Machines Based on an Improved Observer-Structure," IEEE Trans. Power Electron., vol. 19, no. 6, pp. 1562-1567, Nov. 2004.

[8] Hongrae Kim and T. M. Jahns, "Current control for AC motor drives using a single DC link current sensor and measurement voltage vectors," in Fourtieth IAS Annual Meeting. Conference Record of the 2005 Industry Applications Conference, 2005., 2005, vol. 1, pp. 759-765.

[9] H. Kim and T. M. Jahns, "Current Control for AC Motor Drives Using a Single DC-Link Current Sensor and Measurement Voltage Vectors," IEEE Trans. Ind. Appl., vol. 42, no. 6, pp. 1539-1547, Nov. 2006.

[10] J. Xu and Y. Tang, "AC Current Sensorless Control of Three Phase Three-Wire PWM rectifiers under the Unbalanced Source Voltage," in 2006 5th International Power Electronics and Motion Control Conference, 2006, vol. 1, pp. 1-5.

[11] B. Saritha and P. A. Janakiraman, "Sinusoidal Three-Phase Current Reconstruction and Control Using a DC-Link Current Sensor and a Curve-Fitting Observer," IEEE Trans. Ind. Electron., vol. 54, no. 5, pp. 2657-2664, Oct. 2007.

[12] Y. Jie and Yu-peng Tang, "AC current sensorless control of three-phase three-wire PWM rectifiers," in 2008 7th World Congress on Intelligent Control and Automation, 2008, pp. 6516-6520.

[13] Jung-Ik Ha, "Voltage Injection Method for Three-Phase Current Reconstruction in PWM Inverters Using a Single Sensor," IEEE Trans. Power Electron., vol. 24, no. 3, pp. 767-775, Mar. 2009.

[14] Yikun Gu, Fenglei Ni, Dapeng Yang, and Hong Liu, "A novel phase current reconstruction method using a single DC-link current sensor," in 2009 International Conference on Mechatronics and Automation, 2009, no. 2006 , pp. $4874-4879$.
[15] Jung-Ik Ha, "Current Prediction in Vector-Controlled PWM Inverters Using Single DC-Link Current Sensor," IEEE Trans. Ind. Electron., vol. 57, no. 2, pp. 716-726, Feb. 2010.

[16] B. Metidji, N. Taib, L. Baghli, T. Rekioua, and S. Bacha, "Low-Cost Direct Torque Control Algorithm for Induction Motor Without AC Phase Current Sensors," IEEE Trans. Power Electron., vol. 27, no. 9, pp. 4132-4139, Sep. 2012.

[17] B. Hafez, A. S. Abdel-Khalik, A. M. Massoud, S. Ahmed, and R. D. Lorenz, "Single-Sensor-Based Three-Phase Permanent-Magnet Synchronous Motor Drive System With Luenberger Observers for Motor Line Current Reconstruction," IEEE Trans. Ind. Appl., vol. 50, no. 4, pp. 2602-2613, Jul. 2014.

[18] C. Gan, J. Wu, S. Yang, and Y. Hu, "Phase Current Reconstruction of Switched Reluctance Motors From DC-Link Current Under Double High-Frequency Pulses Injection," IEEE Trans. Ind. Electron., vol. 62, no. 5, pp. 3265-3276, May 2015.

[19] I. Aminoroaya and S. Vaez-Zadeh, "Permanent magnet synchronous motor control using DC-Link current regulation," in IECON 2016 - 42nd Annual Conference of the IEEE Industrial Electronics Society, 2016, pp. 7077-7082.

[20] Zhemin Hu; Ming Yang; Kaixuan Yang; Dianguo Xu, "Current Sensorless Direct Predictive Control for Permanent-Magnet Synchronous Motor Drives," in PCIM Asia 2016; International Exhibition and Conference for Power Electronics, Intelligent Motion, Renewable Energy and Energy Management; Proceedings of, 2016, pp. $1-8$.

[21] Y. Yu, X. Chen, and Z. Dong, "Current sensorless direct predictive control for induction motor drives," in 2017 IEEE Transportation Electrification Conference and Expo, Asia-Pacific (ITEC Asia-Pacific), 2017, no. August, pp. 1-6.

[22] A. Kraemer, V. Heusinger, S. Schad, and A. Ali, "Sensorless vector control of PMSM with observer-based phase current reconstruction using only a DC-link current sensor," in 2017 IEEE International Symposium on Sensorless Control for Electrical Drives (SLED), 2017, pp. $145-150$.

[23] M. Bala, I. Bahri, A. Mercier, M. Khanchoul, and G. Krebs, "A Speed PMSM Control Technique With a Single DC Bus current Sensor," in IECON 2019 - 45th Annual Conference of the IEEE Industrial Electronics Society, 2019, vol. 1, pp. 243-248.

[24] M. Manohar and S. Das, "Current Sensor Fault-Tolerant Control for Direct Torque Control of Induction Motor Drive Using Flux-Linkage Observer," IEEE Trans. Ind. Informatics, vol. 13, no. 6, pp. 2824-2833, Dec. 2017.

[25] Y. Azzoug, R. Pusca, M. Sahraoui, A. Ammar, R. Romary, and A. J. Marques Cardoso, "A Single Observer for Currents Estimation in Sensor's Fault-Tolerant Control of Induction Motor Drives," in 2019 International Conference on Applied Automation and Industrial Diagnostics (ICAAID), 2019, pp. 1-6.

[26] D. Luenberger, "An introduction to observers," IEEE Trans. Automat. Contr., vol. 16, no. 6, pp. 596-602, Dec. 1971.

[27] C. J. V. Filho, F. P. Scalcon, T. S. Gabbi, and R. P. Vieira, "Adaptive observer for sensorless permanent magnet synchronous machines with online pole placement," in 2017 Brazilian Power Electronics Conference (COBEP), 2017, pp. 1-6. 